\title{
AS CIDADES GLOBAIS E AS REIVINDICAÇÕES CIDADÃS
}

\author{
Elenise Felzke Schonardie ${ }^{1}$ \\ Ana Maria Foguesatto ${ }^{2}$
}

\section{Resumo:}

O artigo aborda a temática da globalização e das cidades globais. Objetiva analisar o exercício da cidadania no espaço urbano a partir das cidades globais. Reitera a importância dos direitos humanos apresentando elementos para a promoção e melhoria da qualidade de vida da população urbana e demonstra que as cidades globais podem ser um cenário para novas reivindicações cidadãs, em especial daqueles desfavorecidos, na luta para firmar e garantir a cidadania. Conclui que as cidades globais não se constituem apenas em centros de poder econômico, tecnológico e político de importância global, mas, também, como um local de novas reivindicações cidadãs.

Palavras-chave: Cidades globais, Cidadania, Globalização, Reivindicações cidadãs.

\section{GLOBAL CITIES AND CITIZEN CLAIMS}

\begin{abstract}
:
The article addresses the theme of globalization and global cities. It aims to analyze the exercise of citizenship in urban space from global cities. It reiterates the importance of human rights, presenting elements to promote and improve the quality of life of the urban population and demonstrates that global cities can be a scenario for new citizen demands, especially those underprivileged, in the struggle to establish and guarantee citizenship. It concludes that global cities are not only centers of economic, technological and political power of global importance, but also a place of new citizen demands.
\end{abstract}

Keywords: Citizenship, Citizen claims, Globalization, Global cities.

\section{INTRODUÇÃO}

\footnotetext{
${ }^{1}$ Doutora em Ciências Sociais, Mestre em Direito; Graduada em Direito; Professora do Programa de PósGraduação em Direito, Curso de Mestrado e Doutorado em Direitos Humanos da Universidade Regional do Noroeste do Estado do Rio Grande do Sul - UNIJUI; Vinculada a linha de pesquisa " Democracia, Direitos Humanos e Desenvolvimento", membro do Grupo de Pesquisa "Direitos Humanos, Governança e emocracia", Membro da ReDRI. Professora do Curso de Graduação em Direito da UNIJUÍ. Orcid ID: https://orcid.org/00000002-9240-5886; CV: http://lattes.cnpq.br/0918929438055294 ; ID Lattes: 0918929438055294; e-mail elenise.schonardie@unijui.edu.br

2 Mestre em Direito pela Universidade Regional do Noroeste do Estado do Rio Grande do Sul - UNIJUí, Bacharela em Direito pela UNIJUÍ. Doutoranda do Curso de Doutorado em Direito da UNIJUí; Membro do Grupo de Pesquisa "Direitos Humanos, Governança e Democracia". Lattes: http://lattes.cnpq.br/8326506387572525. Orcid: https://orcid.org/0000-0003-0026-2943. E-mail:
} anafoguesatto@hotmail.com. 
O presente artigo aborda a temática da globalização, delimita o tema com as cidades globais como produto de globalização e suas repercussões para exercício da cidadania no meio urbano na contemporaneidade. O objetivo é compreender aspectos das cidades globais, em especial os relacionados a cidadania por meio da livre expressão em movimentos reivindicatórios que visam uma melhor qualidade de vida nos espaços urbanos, nas lutas para firmar e garantir a dignidade da pessoa humana.

Analisa a cidadania e o seu exercício no espaço urbano sob a lógica da globalização e das cidades globais, bem como, demonstrar que as cidade globais podem ser, também, um cenário para novas reivindicações no urbano, em especial daqueles sujeitos em situação de vulnerabilidade econômica e social. Utiliza-se inicialmente a base conceitual do termo cidadania, avançando-se para o exercício da cidadania no espaço público, ainda, procura-se contemplar algumas reivindicações ocorridas nos últimos tempos com exemplos concretos das novas reivindicações que tem surgido no espaço urbano, em especial no espaço urbano de cidades globais.

O texto tem uma matriz teórica, baseada nos estudos contemporâneos acerca da globalização e das cidades globais, que propõe um pensar e repensar na cidade como espaço de desenvolvimento da vida cotidiana e, local de novas reivindicações, sejam favoráveis ou contrárias a lógica excludente da hipermobilidade transnacional do capital e da tecnologia. $\mathrm{Na}$ elaboração do estudo foram observados como método de abordagem o hipotético dedutivo, como método de procedimento o bibliográfico, com a coleta de dados indiretos e, por fim, optou-se pelo método de interpretação o jurídico-sociológico, na medida em que compreendemos que o direito e a globalização são fenômenos culturais em constante mutação.

\section{CIDADANIA E ESPAÇO URBANO NA LÓGICA DA GLOBALIZAÇÃO ECONÔMICA}

O termo cidadania abrange um conjunto de direitos e obrigações à um determinado conjunto de pessoas (cidadãos), de ter a possibilidade de influência na vida pública no lugar onde vivem, tanto de forma direta como indireta. Segundo Dalmo de Abreu Dallari (2004), é possível dizer que aquelas pessoas que não participam de forma ativa da vida pública em prol de seus direitos, encontram-se marginalizados ou excluídos da vida perante a sociedade. 
Para um melhor esclarecimento histórico, Darcísio Corrêa (2002) contribui com informações básicas, nos expondo que a palavra cidadania iniciou a ter efeitos na Roma antiga, e essa designava a situação política de uma pessoa, bem como os direitos que podia exercer enquanto cidadão. Havia nesta sociedade, uma divisão que se dava através de várias categorias, como por exemplo o direito de liberdade, onde a diferenciação era entre homens livres e homens escravos, outra categoria, era a dos patrícios e plebeus, cujo patrícios eram membros das famílias mais importantes e fluentes na economia local, com poderes e influência política, eram considerados nobres, já do segundo grupo, os plebeus, faziam parte as pessoas comuns, que não tinham direito de participar da vida política. Entretanto, os romanos que eram livres e possuíam cidadania, muitas vezes, alguns destes eram impedidos de participar das atividades políticas e administrativas. Diante disso, faziam uma clara distinção entre cidadania e cidadania ativa, sendo que somente os cidadãos ativos podiam participar das atividades públicas.

O conceito de cidadania adotado na França no século 18, foi extraído da história romana, a partir deste século, passou a ser adotada e introduzida nas legislações modernas fazendo a distinção entre cidadania e cidadania ativa. Segundo Dallari (2004, p. 23):

\begin{abstract}
A cidadania, que no século XVIII teve sentido político, ligando-se ao princípio da igualdade de todos, passou a expressar uma situação jurídica, indicando um conjunto de direitos e deveres jurídicos. Na terminologia atual, cidadão é o indivíduo vinculado à ordem jurídica de um Estado. Essa vinculação pode ser determinada pelo local do nascimento ou pela descendência, bem como por outros fatores, dependendo das leis de cada Estado. Assim, por exemplo, o Brasil considera seus cidadãos, como regra geral, as pessoas nascidas em território brasileiro ou que tenham mãe ou pai brasileiro.
\end{abstract}

Diante desta colocação, é possível perceber a importância da cidadania para o desenvolvimento da democracia, e as modificações ocorridas no decorrer da história, a partir da Revolução Francesa de 1789, até os dias atuais. Cidadania além de ser uma qualidade é uma condição do cidadão, é um direito conquistado, diariamente, no que diz respeito a nacionalidade, essa é um pressuposto para o exercício dos direitos políticos, bem como a participação da vida política.

A origem do discurso dos direitos humanos é um dos elementos caracterizadores do início da modernidade e consequentemente da formação do Estado moderno. Autores como Marshall, efetuaram as primeiras discussões sobre as questões urbanas de cidadania, onde a 
sociedade civil era sociedade urbana, pois foi no âmbito das cidades que surgiu a distinção entre público e privado, sendo esta uma característica indispensável para se pensar em cidadania. (CORRÊA, 2002).

No Brasil, os primeiros atos da cidadania expressavam-se a partir do Estado e era seletivo restritamente para aqueles indivíduos que laboravam formalmente à serviço do Estado. E, somente, com a promulgação da Constituição Federal Brasileira de 1988, o exercício da cidadania restou assegurado à todos os cidadãos brasileiros, conforme disposto em seu artigo $1^{\circ}$, inciso II, parágrafo único. O estado democrático brasileiro tem dentre os seus fundamentos a cidadania e o exercício do poder emana do povo, através de seus representantes. (BRASIL, 2018).

A cidadania compreende a participação dos cidadãos da vida e do governo, ou seja, é um vínculo jurídico e político que o indivíduo mantem com o Estado. Diante do parágrafo único, do artigo $1^{\circ}$ do referido texto constitucional, é possível perceber que aos cidadãos brasileiros é garantido esse direito, uma vez que o mesmo declara que "todo poder emana do povo". Ademais, importante é ressaltar que os direitos à cidadania são também deveres:

\begin{abstract}
Pode parecer estranho dizer que uma pessoa tem o dever de exercer seus direitos, porque isso dá a impressão de que tais direitos são convertidos em obrigações. Mas a natureza associativa da pessoa humana, a solidariedade natural característica de humanidade, a fraqueza dos indivíduos isolados em enfrentar o Estado ou grupos sociais poderosos são fatores que tornam necessária a participação de todos nas atividades sociais. Acrescente-se a isso a impossibilidade de viver democraticamente se os membros da sociedade não externarem suas opiniões e sua vontade. Tudo isso se torna imprescindível que os cidadãos exerçam seus direitos de cidadania. (DALLARI, 2004, p. 25).
\end{abstract}

Através do conceito de cidadania é que se afirmam os direitos fundamentais da pessoa humana, para uma boa e essencial convivência entre os cidadãos. Assim, acentua-se também o dever de participação popular que é característica inerente à cidadania, conjugandose assim, os aspectos individuais e sociais. Desse modo, é possível dizer que o Brasil é um país que prevê e pratica a cidadania, a qual é indispensável para constituição de um Estado Democrático de Direito, contribuindo assim, para a efetivação dos direitos humanos no país. (DALLARI, 2004).

O exercício da cidadania nos espaços públicos, objetiva a realização democrática de uma sociedade, compartilhada por todos os indivíduos ao ponto de garantir à todos o acesso à esses espaços e condições de sobrevivência digna, tendo como valor frente a plenitude da 
vida. Isso exige organização e articulação política da população voltada para a superação da exclusão existente.

A evolução da cidadania junto com o desenvolvimento dos direitos humanos, vem se mostrando de forma cada vez mais progressiva. Os modernos ideais dos direitos humanos buscam defender os indivíduos perante o Estado, ou seja, dos excessos coercitivos do poder estatal. Esses ideais que construíram os princípios políticos e jurídicos, visando à consolidação de um conjunto de direitos fundamentais.

\begin{abstract}
Recordando a sistematização de Bobbio, em A era dos direitos, os direitos humanos surgem em uma evolução histórica, assumindo diferentes significados e abrangência em cada período e contexto geográfico. Da mesma forma como ocorreu com a formulação das sucessivas gerações (ou dimensões) de direitos de cidadania individual e política, social e transindividual -, faz-se necessário na atualidade promover uma transposição do caráter abstrato dos direitos fundamentais tradicionais para o contexto do cenário urbano. (BELLO, 2013, p. 238, grifo do autor).
\end{abstract}

Observa-se que a expressão cidadania é vinculada a noção de direitos humanos vindo na forma de direitos civis e direito de liberdade. “[...] Igualdade e liberdade formais desenham o novo status da Cidadania." (CORRÊA, 2002, p. 212). A cidadania consiste num conjunto de direitos e deveres do indivíduo que perante o Estado caracterizam a democracia. A cidadania reflete fundamentos de igualdade: todos são iguais perante a lei e todos têm o direito de participar, direta ou indiretamente, do processo de elaboração dessas mesmas leis.

[...] conceito de cidadania no contexto da modernidade: a cidadania enquanto igualdade humana básica da participação na sociedade, concretizada através da aquisição de direitos. Já Alfred Marshall entendia a cidadania como '...uma espécie de igualdade humana básica associada com um conceito de participação integral da comunidade' (Marshall, 1967, p. 62), mesmo num sistema de desigualdade econômica de classes sociais. (CORRÊA, 2002, p. 211).

O exercício pleno da cidadania é de um modo geral, a prática dos direitos e deveres garantidos aos indivíduos dentro de um Estado, a qual pressupõe uma igualdade humana para todos os cidadãos, bem como à todos os benefícios e implicações decorrentes de uma vida em sociedade.

[...] o homem visto como cidadão (animal social-político), se realiza e se plenifica eticamente na polis: o homem enquanto cidadão (sua causa final diferente da do escravo) é virtuoso e justo enquanto busca atingir a realização plena de sua natureza social na comunidade política. A polis, entendida também como um ser da natureza 
e não como construção humana, tem sua própria causa final se o fim supremo: constituir-se em espaço no qual os cidadãos vivam bem e virtuosamente. (CORRÊA, 2002, p. 140).

A justiça como dimensão simbólica e fundamental do exercício do direito, aperfeiçoa-se na convivência em sociedade, na busca justa pela dignidade do homem enquanto cidadão. "[...] A causa final e suprema do cidadão é viver bem, o que é alcançado pela prática da justiça." (CORRÊA, 2002, p. 141). Ou seja, a justiça se teoriza como princípio ordenador das relações sociais ${ }^{3}$ na busca do bem viver e da qualidade de vida nas cidades.

A organização urbana, baseada na justiça social associa-se em um princípio ético central e universal, que é o princípio fundamental da vida, para referenciar o modo de organização do espaço público para convivência social e sobrevivência dos cidadãos. “[...] Nesse sentido elegemos a afirmação da vida como princípio fundamental, como valor preponderante, capaz de nortear a proposta política de mudança social voltada para a vivência da Cidadania." (CORRÊA, 2002, p. 151).

A cidadania e o espaço urbano se complementam entre si, sendo assim, é pertinente mencionar alguns novos direitos urbanos da cidade através dê dois exemplos trazidos por Bello (2013): o primeiro deles, chamado de direito à cidade, onde o espaço urbano é configurado de forma geopolítica, sendo possível correlacionar em apenas um direito a função social da cidade, democracia participativa e, ainda, os direitos ambientais. O segundo, compreende uma reinvenção da cidade em cidade cidadã, qual representa os seguintes direitos:

(i) direito ao lugar e à moradia; (ii) direito ao espaço público e à monumentalidade; (iii) direito à beleza; (iv) direito à identidade coletiva dentro da cidade; (v) direito à mobilidade e à acessibilidade; (vi) direito à centralidade; (vii) direito à conversão da cidade marginal ou ilegal em cidade de cidadania; (viii) direito à cidade metropolitana ou plurimunicipal; (ix) direito ao acesso e ao uso das tecnologias de informação e comunicação; (x) direito à cidade como refúgio; (xi) direito à proteção por parte do governo, de proximidade diante das instituições políticas superiores e das organizações e empresas prestadoras de serviços; (xii) direito à justiça local e à segurança; (xiii) direito à ilegalidade; (xiv) direito ao emprego e ao salário cidadão; (xv) direito à qualidade do meio ambiente; direito à diferença, à intimidade e à eleição dos vínculos pessoais; e (xvii) direito de todos os residentes em uma cidade a ter o mesmo status político-jurídico de cidadão. (BORJA; MUXI, 2003, p. 124-129 apud BELLO, 2013, p. 239, grifo do autor).

Esses novos direitos urbanos de cidadania, acima elencados são de suma importância para uma convivência harmônica nas cidades. O processo de formação desses direitos urbanos

\footnotetext{
3 “"...] O teórico mais representativo do século XX que se dedicou à feitura de uma teoria da justiça como princípio ordenador das relações sociais foi John Rawls." (CORRÊA, 2002, p. 142).
} 
estão relacionados com as transformações que surgiram de atuações novas e subjetivas na seara social, ou seja, novos movimentos sociais urbanos que envolvem a esfera política.

Algumas transformações ocorridas nas últimas décadas vieram a modificar significativamente os espaços urbanos contemporâneos. A chegada da globalização determinou uma nova hierarquia dos espaços e uma nova reorganização física, econômica e social nas cidades. Após essa reestruturação é que acontece uma expansão no setor da informalização, qual caracteriza-se pela expansão das atividades de trabalho comunitário e informal. "Em larga medida a informalização representa uma nova forma de relação espoliativa, de forma que essas atividades se desenvolvem paralelamente ou pela maneira integrada ao restante da economia." (LEVY, 1997, p. 35).

Em um cenário de globalização, um dos elementos que determinam a configuração de um território, são as empresas transnacionais (ETNs), os Estados, bem como as práticas desenvolvidas nos lares (famílias) e nas comunidades. Assim os fluxos nacionais e o padrão de solidariedade espacial tem grande importância para os fluxos globais de capital e também de população.

As grandes cidades conquistaram uma visão mundial, na busca de reestruturação da metrópole, cabe citar qual é o sentido da cidade mundial na contemporaneidade:

\begin{abstract}
as principais regiões urbanas nessa rede na qual a maior parte dos ativos mundiais estão concentrados, regiões que desempenham um papel crucial na grande estratégia capitalista de organizar o mundo para extração eficiente do excedente... a economia mundial é definida por um conjunto de mercados e unidades de produção, organizado e controlado pelo capital transnacional; cidades mundiais constituem a manifestação material desse controle, ocorrendo somente em regiões centrais ou semiperiféricos onde elas servem como centros financeiros e de bancos, sedes administrativas, centros de controle ideológico. (FRIEDMAN e WOLFF, 1982, citado por KING, 1990, apud LEVY, 1997, p.37).
\end{abstract}

A partir desse conceito, cabe aferir que as cidades globais, também são conhecidas como metrópoles mundiais ${ }^{4}$, foram construídas a partir de instituições econômicas anteriores, de culturas dos antepassados, das políticas e das religiões que vigoravam durante o período colonial.

Levy (1997) aborda outras características para denominar cidade mundial: a) pontos nodais de relação entre a economia mundial e o território do Estado Nacional; b) estrutura

\footnotetext{
${ }^{4}$ Cidades globais e cidades mundiais ou metrópoles mundiais são sinônimos, é apenas uma denominação usada por Levy (1997) pela preferência do uso do termo.
} 
ocupacional que comporta uma elite internacional altamente remunerada; c) essa mesma estrutura ocupacional, leva a um efeito de polarização social (distinção das classes mais e menos favorecidas); d) o surgimento de transformações urbanas (ocupação do solo para construção de grandes edifícios); e) uma perda crescente de controle local e da capacidade de regulação sobre o capital (gastos públicos e empreendimentos); e, f) conflitos políticos resultantes de demandas contraditórias (interesses do capital internacional versus necessidades locais).

Denota-se de grande importância o capital econômico internacional para a construção e bom funcionamento técnico de uma cidade por um viés mundial. Ainda, destacase de um ponto de vista negativo, dentro do espaço metropolitano a perda de solidariedade, qual pode-se verificar através de uma sociedade espacial segregacionista existente. Essa segregação gera exclusão. “[...] O maior desafio contemporâneo é a construção de uma nova ordem social, capaz de mudar tal perspectiva de exclusão. [...]” (CORRÊA, 2002, p. 149).

Assim, o exercício da cidadania pode ser realizado de formas diferentes de acordo com o "lugar" ocupado por cada indivíduo. E, ainda, que no atual contexto social verifica-se a existência de uma crise da democracia e, essa é derivada da ausência de um espaço que seja capaz de lidar com a complexidade técnica, econômica, social e com o pluralismo cultural, dando ensejo a conflitos sociais para construção da cidadania nos espaços urbanos e para a inovação da vida em sociedade.

A sociedade civil é um espaço de relações de poder, reunindo estudo e teorias a esse respeito, Ênio Waldir da Silva (2014), esclarece que a sociedade civil conta hoje com novas percepções na esfera social e pública, como a capacidade de comunicação na forma de diálogos e projetos socializadores, na dedicação para com a economia local, as relações afetivas (familiares), entre outras características que vão muito além das organizações partidárias e políticas, possui comunicação de forma aberta na busca de valores para emancipação social, que preservem as formas de autonomia e solidariedade e é essa a noção que queremos resgatar ao discutir o sentido da cidadania.

Observa-se assim, “[...] que cidadania e sociedade civil são noções diferentes: ao passo que a primeira é reforçada pelo Estado, a última abrange os grupos em harmonia ou conflito. [...]" (SILVA, 2014, p. 117). A sociedade civil trabalha de forma a buscar e lutar pela cidadania em seu âmbito, mesmo sem se tratar da esfera estatal, mas assegurada por 
sanções legais. Cria grupos de apoio a determinadas opções políticas, para que resulte em favorecer a cidadania.

A cidadania vivenciada na prática promove a reativação das esferas públicas existentes e cria outras para que os indivíduos possam agir coletivamente e se empenhar em deliberações, vigilância com as instituições e medidas de resultados. (SILVA, 2014, p. 118).

É imprescindível o pleno exercício da cidadania para constituir uma política justa, com valores solidários e democráticos. Logo, o exercício da cidadania implica discutir a questão da educação para a cidadania, ou seja, não é apenas um conjunto de direitos, é também a participação responsável dos cidadãos. Assim, a cidade deve ser, portanto, o lugar do exercício pleno da cidadania. Isso significa que, não só a cidade deve proporcionar as condições para que o ser humano se desenvolva material e culturalmente, mas que a própria cidade deve ser fruto do desejo e obra de todos os seus cidadãos. Assim, a política de desenvolvimento urbano deve ser fruto desse exercício.

O direito à cidade é muito mais do que um direito à moradia, é o direito a uma vida digna e de qualidade. A construção de uma cidade de todos e para todos, demanda um fórum permanente de debates políticos entre os setores administrativos e a sociedade por uma agenda social que se traduza em leis, planos e ações em prol da concretização da dignidade humana.

No âmbito das cidades, o conceito de espaço público tem por base a acessibilidade e liberdade de circulação e de manifestação de toda a população, sem distinções. Contudo, a cidade contemporânea associada às transformações vividas ao longo da trajetória da evolução urbana, tem modificado a potencialidade do espaço público, para fazer-se representar como um lugar de encontro, bem como, privilegiando o setor comerciário e elevando a economia local.

\footnotetext{
Quando se refere ao mundo globalizado, a expressão sociedade civil procura reunir potenciais e capacidades de democratizar, descentralizar e reorganizar um poder compartilhado diferente das formas atuais das instituições interestatais e capitalistas globais. (SILVA, 2014, p. 122, grifo do autor).
}

$\mathrm{Na}$ contemporaneidade, a sociedade civil buscar reunir esforços para reforçar as iniciativas democráticas nas cidades globais. Com a globalização da economia as cidades passaram a ser vistas como empresas, aliando-se a processos de trabalho, a diferentes estilos de vida e de valores culturais, onde os ambientes construídos passaram a ter temporalidades 
diferenciadas. Assim, destaca-se a importância do planejamento urbano, para definir as regras e exercer o controle e o funcionamento citadino.

É nas cidades que se produz e reproduz a política e seus efeitos, é onde organiza-se a vida institucional enquanto cidadão. O espaço urbano é o local perfeito para se refletir acerca dos aspectos da cidadania, bem como, as suas dimensões. A cidade é palco de diversos movimentos sociais que expressam a dinâmica política e social principalmente das grandes cidades contemporâneas. Ainda, cabe ressaltar que o exercício da cidadania contribui "para evolução dos modelos de direitos clássicos, indicando o urbano como referencial para se reconhecer as necessidades sociais." (BELLO, 2013, p. 291).

O direito à cidadania implica na convivência em sociedade, bem como na construção de relações, na conscientização e reivindicação por direitos. Impulsiona o cidadão a desenvolver suas potencialidades e conscientizar-se de seu dever de fazer a diferença na construção de cidades justa, livres e solidárias, fortalecendo questões éticas, de democracia e direitos humanos.

\section{REPENSANDO AS AÇÕES NOS ESPAÇOS URBANOS PARA CONCRETIZAÇÃO DA DIGNIDADE HUMANA: A CIDADE GLOBAL COMO CENÁRIO PARA NOVAS REIVINDICAÇÕES}

Em uma perspectiva econômica, as cidades abordam um contexto lógico quantitativo, pela visão econômica baseada no retorno de investimentos. No entanto, tanto o empreendedor quanto o consumidor baseiam-se em elementos que são intangíveis na hora de escolher o lugar ideal para se estabelecer, lugar esse que primeiramente lhe ofereça qualidade de vida, mas também que satisfaça desejos pessoais subjetivos. Sendo assim, é a partir desse entendimento que devemos pensar na cidade como um ambiente além de atrativo, mais humano.

Nesse sentido, é necessário pensar sobre a cidade a partir dela mesma, para além de sua dimensão econômica, analisando seu conceito, para então trabalhar o que é melhor para ela e para o bem da coletividade. A valorização do espaço urbano, deve ser repensada considerando os fatores sociais, culturais, ambientais e econômicos, dando ênfase no crescimento populacional no tempo que vivenciamos, sem prejudicar a mobilidade e a integridade urbana. 
No contexto das cidades globais as mudanças baseiam-se, em regra, em torno de atividades da economia global, desenvolvendo uma formação de novas geografias da centralidade, para constituição de novos processos de globalização. Logo, considerando a cidade global um centro do poder econômico e tecnológico em que as decisões se irradiam globalmente, é importante pensar que nessa dinâmica urbana existe um elo entre as diversas mudanças paradigmáticas que são tendência na atualidade, a partir desse cenário surge a necessidade de se repensar a essência da cidade, através do planejamento de novos alinhamentos políticos.

Sassen (2010) questiona a importância de recuperar o lugar e a produção da economia global nas grandes cidades.

\begin{abstract}
É porque ambos nos permitem enxergar a multiplicidade de economias e culturas de trabalho em que está enraizada economia global da informação. Além disso, também nos permitem recuperar os processos concretos e localizados pelos quais a globalização toma forma e argumentar que grande parte do multiculturalismo das grandes cidades é tanto parte da globalização quanto são as finanças internacionais. (SASSEN, 2010, p. 86).
\end{abstract}

Sendo a cidade global reestruturada como uma nova geografia da centralidade, abarca aspectos importantes, que vão muito além da economia e finanças internacionais, que são as questões da multiculturalidade, as quais estão cada vez mais presente nos territórios urbanos. “[...] ligadas à globalização tecnológica, em razão das muitas formas de informatização observamos o surgimento e ascensão de escalas subnacionais, como no caso das cidades globais, e supranacionais, como no caso dos mercados globais, [...] (PIAIA; SCHONARDIE, 2020, p.112).

Sassen (2010, p. 88) afirma que: “[...] A cidade juntamente com a região metropolitana, é um dos espaços onde grandes tendências macrossociais se materializam e assim podem ser constituídas como objeto de estudo. [...]" Nesse contexto, estudar cidades significa compreender os aspectos da vida e da formação urbana, além disso, envolve estudar a história, bem como os principais processos sociais vividos ao longo do tempo. Foi a partir do pensamento da sociologia urbana que passou-se a averiguar que problemas e conflitos locais eram na verdade problemas de cunho social.

O desafio atual consiste em reestruturar o espaço das cidades globais dentro do contexto da globalização e proliferação das dinâmicas transnacionais e translocais. Examinar esses elementos é necessário para promoção de estratégias e melhor compreensão das principais questões críticas vividas, atualmente, nos centros urbanos. Aqui, destaca-se a escola 
da sociologia urbana de Chicago ${ }^{5}$, que já desde o início do século trazia como pauta de seus estudos questões dessa natureza. Ressalvando que, a recuperação do lugar é apenas parcialmente atingido no uso das técnicas de pesquisa da velha escola de sociologia urbana. (SASSEN, 2010).

\begin{abstract}
No trabalho cotidiano do complexo de serviços dominado pelas finanças, uma grande quantidade dos empregos é de baixa remuneração e manual, sendo muitas vagas ocupadas por mulheres e imigrantes. Embora esses tipos de trabalhos e trabalhadores nunca sejam representados como parte da economia global, eles, de fato, fazem parte da infraestrutura dos empregos em volvidos em administrar e implementar o sistema econômico global, incluindo essa forma avançada que são as finanças internacionais. (SASSEN, 2010, p. 94).
\end{abstract}

$\mathrm{Na}$ contemporaneidade, observamos o grande avanço quanto aos direitos das mulheres e imigrantes. Contudo, é necessário muitas mudanças nesse setor, pois os trabalhos manuais e de baixa remuneração, ainda são, na grande maioria realizados pelas mulheres e imigrantes desprovidos de qualificação técnica. Quanto ao giro da economia, para melhor esclarecimento dessa questão, usa-se como exemplo um caminhoneiro, que não faz parte diretamente da produção da economia, mas faz o seu transporte, por mais insignificante que pareça ser, ele é de suma importância para movimentação da economia e para as finanças internacionais. É nesse sentido que deve-se abordar essas questões criando espaços de discussão, representação e intersecção dessas classes.

No âmbito das cidades globais e dos grandes centros urbanos, "Sempre houve desigualdade nas capacidades lucrativas de diferentes setores da economia." (SASSEN, 2010, p. 98). A questão da desigualdade econômica precisa ser enfrentada sendo praticamente impossível uma empresa de pequeno porte, por mais interessante que sejam seus produtos,

\footnotetext{
5 A Universidade de Chicago foi fundada em 1895, graças a generosa doação feita pelo empresário norteamericano John Davison Rockefeller, impulsionando seu crescimento. Entre os anos 1915 e 1940, a Escola de Chicago produziu um vasto conjunto de pesquisas na área social, sobre fenômenos que ocorriam especificamente no meio urbano da metrópole norte-americana. A Universidade começou seu trabalho com um pequeno número de professores e foi crescendo ao longo do tempo. Destaque para Albion Small, que foi o primeiro professor de sociologia e chefe do primeiro Departamento de Sociologia dos Estados Unidos. Tinha a intenção de formar alunos de acordo com o modelo alemão de educação, formando doutores e criando um grupos de professores que saíssem pelos Estados Unidos ensinando a ciência da sociologia. Além disso, fundou a primeira revista de sociologia dos Estados Unidos, a American Journal of Sociology (uma das maiores revistas dos Estados Unidos, na publicação de ideias e pesquisas sociológicas). Small reuniu ao seu redor um grupo de pessoas e elas começaram não só a ensinar sociologia como a trabalhar na edição da revista, bem como a fazer pesquisas sobre a temática na cidade de Chicago. No âmbito da ciência da sociologia, a Escola de Chicago é referencia primária e importante nos estudo dos centros urbanos, qual combinava os conceitos teóricos e as pesquisas de campo de caráter etnográfico. A sociologia urbana era considerada sinônimo de Escola de Chicago. (HOWARD BECKER, 1996).
} 
competir com grandes empresas transnacionais. Os setores de baixa lucratividade acabam sendo realizados por pessoas de baixa escolaridade, mães solteiras ou imigrantes para poder sobreviver, que na grande maioria prestam serviços na informalidade ou de maneira terceirizada. (SASSEN, 2010).

[...] A cidade global emergiu como um local para novas reivindicações: do capital global, e dos novos usuários da cidade e de setores da população urbana em situação de desvantagem, uma presença frequentemente tão internacionalizada quanto os primeiros. A desnacionalização do espaço urbano e a formação de novas reivindicações centradas em atores transnacionais e envolvendo a contestação constitui a cidade global como uma zona de fronteira para um novo tipo de relação. (SASSEN, 2010, p. 107).

As mulheres e os imigrantes ganham destaque como novos usuários das cidades globais, pois dentro desse cenário buscam melhores condições de vida, o que abrange questões de moradia digna, de trabalho remunerado para satisfação dos direitos humanos básicos, reconhecidos pela Organização das Nações Unidas - ONU, mas não adotados sistematicamente por todas as nações e povos do mundo. Sendo a cidade global o lugar perfeito para novas reivindicações em relação ao capital econômico, aos sistemas de produção, surge para o debate a questão da internacionalização desses produtos que transformam a cidade global numa verdadeira fronteira transnacional, e por assim ser, engrandecendo por muitas vezes, os atores internacionais como sendo mais importantes do que os atores nacionais e os locais, que são os que realmente fazem acontecer.

No mundo global destaca-se uma classe de atores desfavorecidos, “[...] a maioria das pessoas envolvidas é bastante imóvel elas não fazem parte de uma classe transnacional viajante ou da nova sociedade civil global de elites internacionais. [...]” (SASSEN, 2010, p. 153). Porém mesmo assim, seja direta ou indiretamente essas pessoas participam de alguma forma desse cenário global.

Sassen (2010), identifica cinco questões que dão mais possibilidades para os desfavorecidos nas cidades globais: primeiramente melhoria nas formas de envolvimento político cívico da população; segundo, afirma a importância da presença de comunidades de imigrantes que produzem formas transacionais específicas para os fluxos globais; terceiro, envolve os modos e possibilidades para os menos favorecidos perante ao poder corporativo global; quarta questão, o acesso aos meios de comunicação principalmente internet de alta qualidade; e a quinta questão refere-se ao questionamento do nível dessas diversas atividades, 
se essas contribuem para desnacionalização da cidade global e se possibilitam novas formas globais de participação mesmo para aquelas pessoas consideradas imóveis.

Logo, entende-se que todas as pessoas, enquanto cidadãos, tem o direito de participação da política local. Ressalva-se a importante função que os imigrantes tem junto as cidades globais, como na produção de bens e produtos diversificados, fazendo novas formas transnacionais. Por conseguinte, uma maneira de dar mais possibilidades e visão do mundo global aos desfavorecidos, seria de modo informativo ou inclusivo deixando-os a par do funcionamento do poder corporativo global. Curiosamente a quarta questão identificada pela autora parece pouco pertinente, mas a verdade, é que conforme o "relatório divulgado pela Comissão de Banda Larga da ONU para o Desenvolvimento Sustentável mostrou que 3,9 bilhões de pessoas no mundo não têm acesso à Internet, o equivalente a 53\% da população mundial." (ONU, 2016). Na quinta e última possibilidade de integração, pontua-se o nível dessas atividades elencadas, se contribuem para a desnacionalização da cidade global, e se há possibilidades de incluir novas formas globais para participação efetiva das pessoas desfavorecidas.

Nesse cenário, observa-se que, cada vez mais, as pessoas em desvantagem reconheçem as características do mundo global. "[...] Assim, o global se torna visível, produzindo uma posição ambígua entre o nacional e o global para atores ativistas, em desvantagem e localizados. (SASSEN, 2010, p. 155).

O britânico, de vertente marxista, David Harvey (2014), trabalha com diversas questões da geografia urbana, e, se auto declara antiglobalização econômica, logo sua posição é radical, se comparada como os estudos de Sassen (2010). Porém, tanto Harvey quanto Sassen concordam que só haverá mudanças se houver a participação da população nas lutas e resistências populares. O perímetro urbano consiste em um espaço de relevante importância para a luta de classes nas últimas décadas, é uma questão de política estratégica organizar o amplo espaço das cidades. Nesse sentido:

Se a urbanização é tão crucial para a história da acumulação do capital, e as forças do capital e seus inumeráveis aliados devem mobilizar-se sem descanso para revolucionar periodicamente a vida urbana, então uma luta de classes de algum tipo, não importa se explicitamente reconhecida como tal, está inevitavelmente envolvida. Isso é assim porque as forças do capital têm de empenhar-se com tenacidade para impor sua vontade em um processo urbano e em populações inteiras que nunca estarão, nem mesmo nas circunstâncias mais favoráveis, sob seu controle total. (HARVEY, 2014, p. 209) 
As manifestações constituem a história das cidades, demonstrando que não é apenas centros urbanos singulares que emerge o espírito de protesto e revolta, mas que esse clamor alastrou-se de forma contagiosa pelas redes urbanas e muitas vezes são responsáveis pelas mudanças nas áreas políticas, sociais e econômicas em todo o mundo. As manifestação cidadãs tem ocorrida com certas desenvoltura e periodicidade, mas por razões aparentemente distintas, nos mais diversos lugares do globo.

Por exemplo, o ano de 1960 marcou os Estados Unidos com uma intensa crise urbana, qual afetou diversas cidades em razão do aumento demográfico que exigia soluções para a vida urbana. Também, no dia 15 de fevereiro de 2003 aproximadamente 3 milhões de pessoas apareceram protestando nas ruas de Roma, uma data histórica pelo início dos movimentos dos direitos civis, essa foi considerada a maior manifestação contra a guerra de toda história da humanidade. (HARVEY, 2014).

No início de segunda década do século 21, a onda de movimentos é liderada, principalmente, por jovens em todo mundo. Destacamos o movimento "Occupy Wall Street" que começou em Nova York e que logo se espalhou por inúmeras cidades norte-americanas (como Boston, Chicago, Los Angeles, Portland e São Francisco) e hoje acontece em cidades do mundo inteiro, inclusive no Brasil. (HARVEY, 2014).

De acordo com o site Hoje na História (2011), o movimento "Occupy Wall Street", foi um protesto que iniciou-se em 17 de setembro de 2011, no Zuccotti Park, distrito financeiro de Wall Street, em Nova York. As principais reivindicações desse movimento eram acerca da desigualdade social e econômica, a corrupção e a grande influência de empresas de grande porte sobre o governo, particularmente do setor de serviços financeiros. O slogan do movimento era "Nós somos os 99\%", representando à desigualdade de distribuição de renda e riqueza nos EUA, comparando-se aos $1 \%$ dos mais rico da população. Os manifestantes foram forçados a sair do Parque Zuccotti em 15 de novembro de 2011. Depois de inúmeras tentativas frustradas de diálogo e acordos com o governo, os manifestantes voltaram a ocupar o local original, que seria ocupação de bancos, sedes corporativas, faculdades e universidades. (HOJE NA HISTÓRIA, 2011).

No ano seguinte, na Espanha, surgiram "Os Indignados". De acordo com o portal Esquerda.net e do PCWorld/Espanha, o manifesto dos "indignados", que repercutiu mundialmente, devido a uma grande onda de desemprego gerada pela crise econômica do ano de 2008, mais de 10 mil pessoas das mais variadas idades entre jovens e idosos, concentraram- 
se na praça Puerta del Sol, em Madrid, nos dias que antecederam as eleições locais e regionais em 22 de maio de 2012. O manifesto tinha por base pedir melhores condições de vida e protestar contra a crise econômica e as políticas antissociais implementadas pelo governo espanhol. $\mathrm{O}$ objetivo era manter-se protestando, inclusive na madrugada, em acampamento improvisado até o dia 22 de maio. Ouve uma rede de voluntários para apoiar e ajudar os manifestantes, foram criadas cinco comissões de auxilio a alimentação, infraestrutura e aconselhamento jurídico.

A praça Puerta del Sol, tornou-se o marco para protestos específicos. As redes sociais ajudaram muito a mobilizar as pessoas em diversas cidades da Espanha, em um movimento que ficou conhecido como "os indignados" que posteriormente ganhou o nome de " $15 \mathrm{M}$ ". Na noite do dia 16 de maio de 2012, a polícia tentou desmontar o acampamento que os manifestantes montaram na praça Puerta del Sol. (CARTA MAIOR, 2019).

No Brasil, acerca de movimentos sociais urbanos, temos como exemplo o Movimento "Passe Livre" (MPL). Segundo o site Tarifa Zero.org (2019), o MPL é um movimento social autônomo, não partidário, horizontal e independente, que tem por objetivo lutar por um transporte público gratuito para a população, fora da iniciativa privada. $\mathrm{O}$ Movimento Passe Livre iniciou de maneira formal em janeiro de 2005, na cidade de Porto Alegre, mas antes disso, há aproximadamente seis anos, já existia uma campanha pelo Passe Livre na cidade de Florianópolis. A horizontalidade do movimento refere-se que esse não tem uma direção centralizada de poder, ou seja, os direitos de participação são iguais para todos. Pois trata-se do interesse de todos, sem exclusão, ter acesso livre e gratuito ao transporte coletivo urbano.

O transporte coletivo urbano é de fundamental importância para o pleno funcionamento das cidades, seus principais usuários são a classe trabalhadora. Nesse sentido, o movimento do Passe Livre buscava melhores condições de acesso a esse serviço urbano básico, que no Brasil, está contemplado como um direito social ao transporte - art. $6^{\circ}$ da Constituição Federal de 1988. Esse movimento repercutiu muito em diversas cidades brasileiras. Contudo, no ano de 2013 começam a surgir grandes manifestações reivindicando melhores condições de vida, trabalho e anticorrupção.

Junho de 2013 expressou uma resistência às formas de mercantilização do trabalho e das terras urbanas manifestada por um desejo de mais democracia e investimentos públicos", afirma o sociólogo da USP Ruy Braga. A mobilização, iniciada como um protesto contra o aumento da tarifa dos ônibus - que passaria de $\mathrm{R} \$ 2,80$ para $\mathrm{R} \$$ 
3,00 — , cresceu proporcionalmente à violência empregada pela Polícia Militar de São Paulo contra os manifestantes (FLORESTI, 2018).

A cidade de São Paulo, capital do estado que leva o mesmo nome, é considerada o coração financeiro da América Latina e, também, como uma cidade global. Os movimentos populares que tomaram suas ruas no início de junho de 2013, acabaram por influenciar outras cidades. "O dia 20 marcou a maior manifestação de junho de 2013, com 1,25 milhão de pessoas nas ruas em 130 cidades." (FLORESTI, 2018, s/p.). Movimentos populares tinham dentre suas reinvindicações uma extensa pauta em investimentos em áreas públicas, novos e diversos diálogos sociais e políticos. Porém, tais manifestações não se caracterizam como as das décadas anteriores, na medida em que não se conseguia identificar um núcleo central de organização vinculado a partidos, organizações ou instituições. A internet foi a principal ferramenta de convocação e articulação desses movimentos, em que os cidadãos manifestaram seu descontentamento com as políticas de mercantilização do trabalho, da terra, da moradia, do custe de vida e da corrupção que mostrava presente nas estruturas do estado e da sociedade.

No ano de 2018, surge na França o movimento coletivo urbano dos "coletes amarelos" (gilet jaunes, em francês) que segundo matéria escrita por João Paulo Charleaux no Jornal Nexo, foi um movimento autodenominado 'espontâneo, horizontal e apartidário' que avançou sobre o governo Macron, com apoio da esquerda populista e da extrema direita" (CHARLEAUX, 2018). O movimento teve início em 17 de novembro de 2018, os manifestantes vestidos com coletes amarelos e fitas refletoras, começaram pelas zonas rurais e subúrbios franceses, logo avançaram aos centro da cidade de Paris, na Champs Elysée, concentrado milhares pessoas. Os manifestantes passaram a convocar protestos através de discursos via redes sociais e juntou cada vez mais apoiadores à causa que em questão de pouco tempo multiplicou o número de apoiadores. (CHARLEAUX, 2018).

O porque do manifesto ter o nome de coletes amarelos, é que na França todos os motoristas são obrigados a ter dentro dos automóveis coletes amarelos, para em caso de acidentes, vestir e ser mais fácil de identificar o sinistro na via. O motivo central do manifesto é reivindicar o preço do combustível na França, por isso, quem está na linha de frente são os que exercem a profissão de motorista, destacando-se principalmente os caminhoneiros. "A pauta, que começou pelos combustíveis, evoluiu para uma insatisfação generalizada com o 'custo de vida' de maneira geral. E daí para pedidos de destituição do presidente francês, 
Emmanuel Macron [...]”. (CHARLEAUX, 2018). Em setembro de 2020 o movimento dos "coletes amarelos" voltou a fazer manifestações em Paris, após seu amortecimento pela crise do coronavírus, conforme o The Guardian (2020).

Portanto, cumpre mencionar que as cidades são o palco perfeito para movimentos urbanos, para expressar através de correntes profundas a lutar por direitos sociais e mudanças políticas de classes $^{6}$, movimentos esses que advém de uma grande insatisfação dos cidadãos urbanos. A cerca de como o governo age perante ao exposto, Harvey, (2014, p. 212) descreve que: “[...] o poder político frequentemente procura regionalizar as infraestruturas urbanas e a vida urbana com o objetivo de manter as populações insatisfeitas sob controle. [...]" Sendo assim, podemos entender que o poder governamental, através de meios pacíficos acaba dividindo a cidade por classes, ou seja não mistura ricos e pobres, mantem a lógica da segregação espacial, social e econômica, da globalização do capital e das finanças.

No período contemporâneo de uma urbanização altamente capitalista de cunho neoliberal, realizar movimentos sociais urbanos é um direito um tanto que complicado de expressar, resta comprovado que os direitos dos desfavorecidos dificilmente vai ser ouvido pela ordem capitalista, ou seja, os que detêm o poder (econômico e tecnológico), porém é preciso continuar a luta por um mundo com menos desigualdades sociais. Nesse sentido, as manifestações reivindicatórias populares urbanas podem ser compreendidas e explicadas como manifestações do direito à cidade.

[...] o direito à cidade deve ser entendido não como um direito ao que já existe, mas
como um direito de reconstruir e recriar a cidade como um corpo político socialista
com uma imagem totalmente distinta: que radique a pobreza e a desigualdade social
e cura as feridas da desastrosa degradação ambiental. Para que isso aconteça, a
produção das formas destrutivas de urbanização que facilitam a eterna acumulação
de capital deve ser interrompida. (HARVEY, 2014, p. 247).

De tal modo, devemos refletir e repensar as nossas ações e atitudes, que por muitas vezes possa parecer insignificante, quando consideradas em âmbito coletivo, podem vir a fazer a diferença para as transformações sociais, territoriais e culturais no urbano. Logo, é necessário medir nossas responsabilidades conjuntamente para concretização dos valore que fundamentam a cidadania e a dignidade humana.

As cidades globais são locais onde denota-se grandes contradições da globalização do capital, onde concentram-se uma quantidade desproporcional de poder e supervalorização

\footnotetext{
${ }^{6}$ Movimentos sociais de classe são aqueles que tem por objetivo lutar por mudanças na ordem social urbana, principalmente quanto às desigualdades existentes.
} 
da economia e das finanças. Todavia, é no perímetro das grandes cidades que concentram-se, cada vez mais, as populações humanas em situação de desvantagem social, moradores de vilas, favelas e periferias, entre esses, imigrantes vindos da Europa e afro-americanos, latinos americanos e migrantes trabalhadores rurais da Ásia. (SASSEN, 2010). É justamente nesse cenário de desigualdades e segregação urbana que se faz emergir novos movimentos sociais em prol da cidadania, seja de grupos minoritários ou excluídos.

[...] A cidade global emergiu como um local para novas reivindicações: do capital global, e dos novos usuários da cidade e de setores da população urbana em situação de desvantagem, uma presença frequentemente tão internacionalizada quanto os primeiros. A desnacionalização do espaço urbano e a formação de novas reivindicações centralizadas em atores transnacionais e envolvendo a contestação constituem a cidade global como uma zona de fronteira para um novo tipo de relação. (SASSEN, 2010, p. 107).

A partir de todos esses processos de mudanças na vida social e política, que reflete-se em conflitos fundados dentro da realidade dos valores comuns dos indivíduos em desvantagem econômica, que por sua vez, encontraram voz na forma de reivindicações para definir novas formas de ações sociais para influir em resultados que fortaleça seus direitos na cidade.

\section{CONCLUSÃO}

Com o propósito de finalizar o presente texto, é pertinente trazer à título de considerações finais alguns apontamentos que confirmam a relevância do trabalho, quais sejam: as cidades globais são produto de globalização econômica, tecnológica e cultural; e o exercício da cidadania nesse cenário é, em tese, desfavorável. Denota-se de alta relevância o assunto abordado, pois seu delineamento trata de algo que diz respeito ao interesse de todos os cidadãos, em que pese salvaguardar seus direitos inerentes a dignidade da pessoa humana, bem como a qualidade de vida nos grandes centros urbanos.

O conceito de cidadania, é de fato, dinâmico e renova-se constantemente no tempo e no espaço, fruto das transformações da sociedade, dos contextos históricos e principalmente das mudanças que englobam paradigmas ideológicos. A cidadania vivida na antiguidade não é a mesma cidadania pela qual lutamos hoje e a que pretendemos ver concretizada para as gerações futuras, tornando-se um desafio a ser enfrentado pelos cidadãos nesta nova era global. Em diferentes contextos, vivencia-se a liberação dos processos de globalização como um novo debate da realidade atual. Assim, busca relacionar a era global com formas de 
reestabelecer a ética da cidadania, como um direito fundamental da pessoa humana, em âmbito local.

A cidade global tornou-se palco, cenário perfeito, das novas reivindicações da população para concretização da dignidade humana e o direito à cidade: o lugar do capital transnacional (global), torna-se, também, o lugar dos novos usuários da cidade e de setores da população urbana em situação de desvantagem e exclusão social. Porém, nesse cenário, há uma preponderância dos interesses econômicos e políticos do capital e das finanças transnacionais sobre as populações locais, em específico sobre os sujeitos e grupos mais vulneráveis, destacando-se dentre estes as mulheres, imigrantes e afrodescentes. Logo, constitui-se imprescindível a elaboração de novas perspectivas para a construção de uma perspectiva que se pretende universal, solidária e intergeracional para compreensão e aceitação das novas reivindicações urbanas, protagonizadas por diferentes sujeitos em favor da dignidade humana e concretização da cidadania e do direito à cidade.

\section{REFERÊNCIAS}

BECKER, Howard. A escola de Chicago. Revista Mana. vol.2 no.2 Rio de Janeiro Oct. $1996 . \quad$ Disponível em: http://www.scielo.br/scielo.php?script=sci_arttext\&pid=S0104-93131996000200008. Acesso em 24 de jan. de 2019.

BELLO, Enzo. A cidadania no luta política dos movimentos sociais urbanos. Caxias do Sul: EDUCS, 2013.

BRASIL. Constituição da República Federativa do Brasil de 1988. Disponível em: http://www.planalto.gov.br/ccivil_03/constituicao/constituicaocompilado.htm. Acesso em 29 nov. 2018.

CARTA MAIOR: O PORTAL DA ESQUERDA. Milhares de manifestantes ocupam o centro de Madri. Foto de EPA/Pablo Talamanca. 2011. Disponível em:

https://www.cartamaior.com.br/?/Editoria/Pelo-Mundo/Milhares-de-manifestantes-ocupam-ocentro-de-Madri/6/16717. Acesso em: 24 jan. 2019.

CHARLEAUX, João Paulo. Quem são os Coletes Amarelos que protestam na França. 2018. Disponível em: https://www.nexojornal.com.br/expresso/2018/11/27/Quem-

s\%C3\%A3o-os-coletes-amarelos-que-protestam-na-Fran\%C3\%A7a. Acesso em: 24 jan. 2019.

CORRÊA, Darcísio. A Construção da Cidadania: Reflexões Histórico-Políticas. 3. ed. Ijuí: Unijuí, 2002.

DALLARI, Dalmo de Abreu. Direitos humanos e cidadania. São Paulo: Moderna, 2004.

FLORESTI, Felipe. Manifestações de 'Junho de 2013' completam cinco anos: o que mudou? Disponível em: 
https://revistagalileu.globo.com/Revista/noticia/2018/06/manifestacoes-de-junho-de-2013completam-cinco-anos-o-que-mudou.html . Acesso em 19 set. 2021.

HARVEY, David. Cidades Rebeldes: do direito à cidade à revolução urbana. Tradução de Jeferson Camargo. São Paulo: Martins Fontes - selo Martins. 2014.

HOJE NA HISTÓRIA. Movimento "Ocupe Wall Street" começa em Nova Iorque. 2011. Disponível em: https://seuhistory.com/hoje-na-historia/movimento-ocupe-wall-street-comecaem-nova-iorque. Acesso em: 24 jan. 2019.

JORNAL NEXO. Quem são os Coletes Amarelos que protestam na França. Benoit Tissier/Reuters. 2018. Disponível em:

https://www.nexojornal.com.br/expresso/2018/11/27/Quem-s\%C3\%A3o-os-coletes-amarelosque-protestam-na-Fran\%C3\%A7a. Acesso em: 24 jan. 2019.

LEVY, Evelyn. Democracia nas cidades globais: um estudo sobre Londres e São Paulo. São Paulo: Studio Nobel, 1997.

ONU. ONU. Mais da metade da população mundial ainda não tem acesso à Internet. 2016. Disponível em: https://nacoesunidas.org/mais-da-metade-da-populacao-mundial-aindanao-tem-acesso-a-internet/. Acesso em: 23 jan. 2019.

PIAIA, Thami C., \& SCHONARDIE, Elenise F. (2020). As tecnologias de informação e comunicação nos espaços urbanos globais e a proposição de cidades inteligentes. Revista Jurídica Da FA7, 17(3), 109-120. https://doi.org/10.24067/rjfa7;17.3:1276

SASSEN, Saskia. Sociologia da Globalização. Tradução de Ronaldo Cataldo Costa. Revisão Téc. de Guilherme G. de F. Xavier Sobrinho. Porto Alegre: Artmed, 2010.

SILVA, Ênio Waldir. Estado, Sociedade Civil e Cidadania no Brasil: bases para uma cultura de direitos humanos. Ijuí: Unijuí, 2014.

TARIFA ZERO.ORG. Movimento Passe Livre. Disponível em: http://tarifazero.org/mpl/. Acesso em: 24 jan. 2019.

THE GUARDIAN. Gilets jaunes protest. Disponível em:

https://www.theguardian.com/world/gilets-jaunes-protests . Acesso em 19 set. 2021. 